PRAMANA

(C) Indian Academy of Sciences

Vol. 76, No. 2

— journal of

physics

February 2011

pp. 191-200

\title{
X-ray spectrometry for preventive conservation of cultural heritage
}

\author{
RENÉ VAN GRIEKEN* and ANNA WOROBIEC \\ Environmental Analysis Group, Micro and Trace Analysis Centre, University of Antwerp, Antwerp, \\ Belgium \\ *Corresponding author. E-mail: rene.vangrieken@ua.ac.be
}

\begin{abstract}
Analytical chemistry does play a key role in the chemical characterization of the environment and it appears that X-ray spectrometry, in its many forms, is one of the most relevant analytical techniques in preventive conservation, as it is in cultural heritage research in general. $\mathrm{X}$-ray spectrometry has indeed been the method of choice for the characterization of the inorganic composition of atmospheric aerosols, for a long time.

We have, over the last decade, intensively used various forms of X-ray spectrometry, viz., mostly energy-dispersive X-ray fluorescence, e.g. with polarized high-energy beam excitation, and automated electron probe X-ray microanalysis, together with other techniques, to identify particle types and their sources in indoor environments, including museums, while gaseous indoor pollutants were assessed using passive diffusion samplers. In each case, both bulk aerosols and individual aerosol particles were studied. For microanalysis of single particles, we have investigated a dozen techniques, but for wide, real-life applications, automated electron probe X-ray microanalysis is the most rewarding.

We have first studied atmospheric aerosols in and around the Correr Museum in Venice, many other museums in Austria, Japan and England, and in the caves with prehistoric rock paintings in Altamira, Spain. Very recently, measurements were done in the Metropolitan Museum of Art in New York and the Wawel Castle in Cracow, in Italian and Polish mountain churches, in a number of museums in Belgium and the Netherlands, and in cathedrals with medieval stained glass windows. In the Correr museum, it appeared that the particles most threatening for the Bellini paintings were released by the deteriorating plaster renderings, and this could be avoided by simply improving the rendering on the museum walls. In the Wawel Castle, outdoor pollution particles, like fine soot from diesel traffic, entering via leaks in the windows and doors, and also street-deicing salts and coal burning pollution particles, brought in by visitors, mostly in winter, were found to be most worrisome.

Urgent questions that are not solved at this moment pertain to the deposition processes from the atmosphere to the cultural heritage items, the critical surface interactions that take place on these items, and the establishment of suitable particle concentration standards.
\end{abstract}

Keywords. Preventive conservation; cultural heritage; X-ray fluorescence; electron probe X-ray microanalysis; atmospheric $\mathrm{SO}_{2}$; aerosol analysis.

PACS Nos 82.80.Ej; 81.70.Jb; 92.60.Sz 


\section{Introduction}

Preventive conservation implies, e.g., the characterization of the atmospheric environment around monuments or cultural heritage items, with the intention of improving these conditions and contributing to the preservation of cultural heritage items. Earlier, much interest was on $\mathrm{SO}_{2}$ and its effect on buildings, but the focus has now been shifted to the indoor environment and to atmospheric particles in, e.g. museums. This paper will, in this context, discuss the following topics: (1) Why is chemical analysis needed for cultural heritage (CH) studies?, (2) Is X-ray spectrometry (XRS) important for $\mathrm{CH}$ studies?, (3) What is 'preventive conservation'?, (4) Examples of aerosol analysis in the context of preventive conservation. Chemical analysis is highly important in $\mathrm{CH}$ studies to answer questions about (a) the techniques and materials that have been used by the artist, (b) the provenance of the materials used and the possible forgery of a work of art and (c) the compatibility of the materials intended to be used for restorations.

XRS techniques are the method of choice in this field, mainly because of their nondestructive nature. In TECHNART2009, the International Conference on Analysis Techniques in Art and Cultural Heritage, that took place in Athens, Greece, 27-30 April 2009, 155 analysis-oriented contributions were presented as lectures or posters. More than 115 of these used X-ray techniques, namely, energy-dispersive X-ray fluorescence (EDXRF), including portable and micro-XRF (60); electron probe X-ray microanalysis (EPXMA or SEM/EDX) (25), X-ray diffraction (XRD) (14), particle-induced X-ray emission (PIXE) (10); X-ray tomography (3) and X-radiography (2). All other analysis techniques were used in, all together, 113 of the contributions, namely, diverse optical techniques (35); infrared spectrometry (26); Raman spectrometry (15); gas chromatography coupled to mass spectrometry (10); nuclear magnetic resonance (6); laser-induced breakdown spectrometry (6); high-pressure liquid chromatography (3); (laser-ablation) inductively coupled mass spectromety (3); neutron diffraction (3); neutron imaging (2); neutron activation analysis (2) and gamma activation analysis (2). This is just one example, but the literature abounds with X-ray application cases. For instance, at the Denver X-ray Analysis Conference (2-6 August 2010), during two days of tutorial workshops, two half days were devoted to X-rays for $\mathrm{CH}$ research, and during the remaining sessions, another two half days were devoted to this topic. All these illustrate the relevance of XRS in this field. There are certainly thousands of published applications of XRS in this field (and recently there is an increased interest in portable XRS); many of these publications are, however, in the 'grey' literature, like conference proceedings, and in internal reports. The applications range from very simple, e.g. the use of radioisotopes to excite characteristic X-rays from statues to identify pigments on them, to highly sophisticated, e.g. the use of threedimensional XRF or confocal XRF to study the depth distribution of elements in paintings at the micrometer scale.

In simple words, $\mathrm{CH}$ conservation means maintaining a work of art in 'good condition'. In addition to intrinsic parameters (e.g. the excessive acidity in papers produced from 1850 to 1950), environmental factors such as local air pollution as well as microclimate and microbiology factors, also affect conservation, also indoors. Studying these environmental conditions (microclimate, microbiology and chemical pollution) around a work of art, with the intention to improve them and to extend the lifetime of a work of 
art is now popular and is called (is included in) preventive conservation. In the field of conservation, the European Union in its 7th Framework Program, has considered only research projects on preventive conservation.

A more comprehensive definition of preventive conservation, by the American Institute for conservation, is the following: "The mitigation of deterioration and damage to cultural property through the formulation and implementation of policies and procedures for the following: appropriate environmental conditions; handling and maintenance procedures for storage, exhibition, packing, transport, and use; integrated pest management; emergency preparedness and response; and reformatting or duplication." It is only the first of these topics that this paper deals with. Although the possibly deleterious effects of the atmospheric environment on works of art has, of course, been known for long, the term 'preventive conservation' has become popular only in the last 20 years.

One of the early (in the 1970s) and well publicized studies on the effects of air pollution on historical buildings has been for the Taj Mahal in Agra, India. The $\mathrm{SO}_{2}$ emissions were found to be responsible for the rapid deterioration of the marble of Taj Mahal. A series of initiatives have been taken then: a natural gas pipeline has been laid to supply clean fuel to industries around Agra, diesel-run three-wheelers have been replaced by CNGfuelled vehicles, and heavy investments have been made in the Mathura refinery to reduce pollution. The so-called 'Taj Trapezium Zone' (TTZ) was defined as an area of 10,400 $\mathrm{km}^{2}$ around the Taj Mahal to protect the monument from pollution. The Supreme Court of India delivered a ruling on 30 December 1996 regarding industries covered under the TTZ. It banned the use of coal/coke in industries located in the TTZ with a mandate for switching over to natural gas, or relocating them outside the TTZ or shutting down.

Many buildings and statues in Europe have also been found to be affected by $\mathrm{SO}_{2}$. The mechanisms of this effect have, in the meantime, been studied and confirmed. $\mathrm{SO}_{2}$ (from impurities in, e.g. coal) transforms the calcite $\left(\mathrm{CaCO}_{3}\right)$ which is the main mineral in marble, limestone and sandstone, into gypsum $\left(\mathrm{CaSO}_{4} \cdot 2 \mathrm{H}_{2} \mathrm{O}\right)$. Compared to calcite, this is more soluble (i.e. it is carried away by rainwater at exposed sites) and more porous (i.e. at sites unexposed to rainwater, the gypsum will absorb more water and be more prone to frost damage in winter, and take up more soot from diesel cars, and hence it will turn black). The mechanism of the 'black crust' formation has been elucidated very well during the last two decades. Nowadays, in Europe, the effect of $\mathrm{SO}_{2}$ on buildings is no longer studied in terms of chemistry and physics, because all is rather well known now, but rather in terms of esthetics, public awareness and public acceptance, i.e., chemistry and physics studies are more or less replaced now by sociology and economy concerns.

In most developed countries, the atmospheric $\mathrm{SO}_{2}$ levels have been reduced significantly in the last three decades, e.g. by more than 60\% in the European Union between 1980 and 2000, and they do not constitute a serious threat there any more. However, other gaseous pollutants, like $\mathrm{NO}_{x}$ from traffic and the resulting ozone, have not been reduced in the meantime, and also the atmospheric concentration of particles (natural ones, like sea salt, or anthropogenic ones, like soot from traffic) has not gone down. At present, preventive conservation in the context of air pollution is mostly concerned with particulate pollution, in the indoor environment. Famous examples are the soiling effects of atmospheric particles on the splendid wall paintings of Michelangelo in the Sistene Chapel in the Vatican in Rome, and on Leonardo da Vinci's Last Supper in Milan. Also for the Taj Mahal, by 


\section{René van Grieken and Anna Worobiec}

the way, the $\mathrm{SO}_{2}$ and $\mathrm{NO}_{x}$ levels are now acceptable, but the dust concentrations remain very high, in the dry season.

As a matter of fact, since 1970, aerosol-loaded filters have been a very important analytical tool for XRS (XRF, but also PIXE, EPXMA) studies. This is simply because they are almost ideal targets (thin, homogeneous) and XRS does not require dissolution of (sometimes refractory) aerosols. This is in contrast with the more popular and widespread atomic absorption spectrometry and inductively-coupled plasma atomic emission spectrometry and mass spectrometry, where the filters have to be dissolved (often in HF to dissolve Si-containing particles), prior to the analysis. Not surprisingly, aerosol analysis have continuously made up around $9 \%$ of the total international literature on XRS, for the last three decades, which is more than that of the metal analysis.

\section{Examples of aerosol analysis in the context of preventive conservation}

In this section, we describe two examples on the use of XRS for aerosols in the context of preventive conservation - an older one in the Correr Museum in Venice, which might still be relevant because of the simple way in which XRS solved a major problem, and a recent/preliminary one which is in fact still in progress: the Wawel Castle Museum in Cracow, Poland. These are representative examples from about 20 studies in different museums in Europe, Japan, USA, Brazil and Argentina, that we have carried out over the last 15 years.

\subsection{Applied analysis techniques}

First, however, let us discuss which analytical techniques have been applied in these studies. For characterizing indoor atmospheric particles and their sources, we used mostly ion chromatography for ionic analysis, gas chromatography coupled to mass spectrometry for organics, aethalometry for soot determination, gravimetry for total mass per $\mathrm{m}^{3}$, XRF for bulk (on loaded filter) elemental analysis and EPXMA for individual microparticle characterization (when you see elements gathering together in one single particle, it is usually much easier to identify the source and source process). Sampling for bulk XRF was simply done by drawing air through a teflon or Nuclepore filter; for single particle analysis by EPXMA, size-segregated sampling was performed using an impactor sampler, e.g. a Berner-type, Harvard-type or May-type impactor, onto Si or Ag substrates.

2.1.1 X-ray fluorescence analysis. For elemental analysis, XRF has the following advantages: It does not require any sample preparation, it permits fast analyses at low cost, simultaneous detection of a wide range of concentrations (from some ppm to several percent) with high precision is possible and it will not be affected by the chemical state of the analyte. This technique can be applied to all elements with $Z>12$, in bulk, liquid or thin layer samples. On the other hand, EDXRF has some disadvantages also: low- $Z$ elements often cannot be determined accurately, due to the presence of a detector window, which prevents the penetration of low-energy X-rays, and spectral interferences can occur because the energy resolution of the detector is limited. 
The EDXRF spectrometer used recently for aerosol analyses [1] in these projects was Epsilon-5 from PANalytical (Almelo, The Netherlands). The spectrometer has a powerful $\mathrm{X}$-ray tube, 3D polarizing geometry (resulting in more favourable detection limits), up to 15 secondary targets and a high-resolution HPGe-detector. Up to 26 elements (Al, Si, P, $\mathrm{S}, \mathrm{Cl}, \mathrm{K}, \mathrm{Ca}, \mathrm{Ti}, \mathrm{V}, \mathrm{Cr}, \mathrm{Mn}, \mathrm{Fe}, \mathrm{Ni}, \mathrm{Cu}, \mathrm{Zn}, \mathrm{As}, \mathrm{Rh}, \mathrm{Pd}, \mathrm{Cd}, \mathrm{Pt}, \mathrm{Pb}, \mathrm{Se}, \mathrm{Sr}, \mathrm{Br}, \mathrm{Sn}, \mathrm{Sb}$ ) were analysed. MicroMatter Co. standards were used for calibration of the Epsilon-5 spectrometer. These standards are thin (Mylar) films of elements prepared by vacuum deposition resulting in a highly uniform deposit. The calibration was checked by analysing the standard CRM 2783 from NIST. In earlier studies, a more economic PANalytical MiniPal-1 and a 'now-aging' Tracor Spectrace-5000 instrument were used.

2.1.2 Electron probe $X$-ray microanalysis. The size-segregated samples were analysed by means of a JEOL 733 electron probe microanalyser equipped with a superatmospheric thin-window EDX using homemade software. This set-up allows measuring low- $Z$ elements, like carbon, nitrogen and oxygen, which are required for 'rough' chemical speciation at the single particle level. Samples were collected on a Si substrate for the Berner impactor stages \#3 and \#4, i.e. for particles with an aerodynamic diameter between 0.25 and $1 \mu \mathrm{m}$, and 100 particles were then measured manually. For Berner impactor stages \#5-8, i.e. particles with aerodynamic diameters from 1 to above $8 \mu \mathrm{m}$, approximately 300 particles deposited on $\mathrm{Ag}$ foils were analysed in an automated mode. To avoid beam damage of the particles on stages $3-6$, the sample holder was continuously cooled by liquid nitrogen. The obtained X-ray spectra from this thin-window or low- $Z$ element EPXMA were evaluated by a nonlinear least squares fitting program. The semiquantitative elemental composition in the particles was calculated with an iterative approximation method based on Monte Carlo simulations [2]. In the next step, the particles were classified using hierarchical cluster analysis (HCA), based on the elemental data obtained by the low- $Z$ EPXMA. The HCA was performed using the integrated data analysis system (IDAS) program [3]. All analysed particles were divided into different clusters (= particle types) according to their elemental similarity, followed by the calculation of the average elemental weight concentrations, average diameters and relative abundances $(\%)$ of each particle type. Particles on different impactor stages were all treated independently.

For the last two decades, we have intensively tried out, for individual particle analysis, the following alternative techniques - TEM: transmission electron microscopy, spottest SEM: scanning electron microscopy combined with microchemical reactions, SAED: small angle electron diffraction analysis, EELS: electron energy loss spectrometry, LAMMA: laser microprobe mass analysis, SIMS: secondary ion mass spectrometry, TOFSIMS: micro-time-of-flight secondary ion mass spectrometry, $\mu$-FTIR: micro-Fourier transform infrared spectrometry, $\mu$-PIXE: microparticle-induced X-ray emission analysis, $\mu$-SXRF: microsynchrotron radiation X-ray fluorescence, $\mu$-LA-FT-ICR-MS: microlaser ablation Fourier transform ion cyclotron resonance mass spectrometry, $\mu$-XANES: micro-X-ray absorption near-edge spectroscopy and MRS: micro-Raman spectrometry. However, we have concluded that for representative analysis (at least 100 particles per sample) and for small particles (down to $0.3 \mu \mathrm{m}$ ), only the automated EPXMA and, in some cases, MRS are the best. 


\section{René van Grieken and Anna Worobiec}

The methodological approaches that we have added to EPXMA of individual aerosol particles during the last decade are: (1) different advanced approaches for the statistical handling of such large data sets, (2) analysis of more volatile particles (using liquidnitrogen cooling of the stage), (3) quantitative determination of low- $Z$ elements (using a thin-window X-ray detector and sophisticated Monte Carlo simulations for quantification) and hence chemical speciation in individual micrometer-size particles.

\section{The case of the Correr Museum in Venice, Italy}

The Correr Museum, on the San Marco Square in Venice, Italy, had a specific problem in the two rooms in which paintings of Bellini (1434/39-1515) were kept. The paintings were gradually turned dark and there was no evident explanation. This problem was studied within the framework of an EU project, in collaboration with microbiologists and microclimate specialists. Four sampling campaigns were organized in the Correr Museum during the 1990s. Most of the results have been published earlier [4,5].

Indoor samples were collected in the Bellini rooms of the museum. Numerous bulk aerosol samples for XRF were taken by filtration; size-segregated aerosol samples for EPXMA were collected by impaction. Also, 33 filters were used to measure the dry deposition inside the museum; they had been attached vertically to the walls, near the paintings, at several heights. Outdoor samples were collected in a window overlooking the San Marco Square. Figure 1 shows that Ca was the main element detected by EDXRF on the indoor filters of the Correr Museum (indicated as CM), followed by Si, S and Cl.

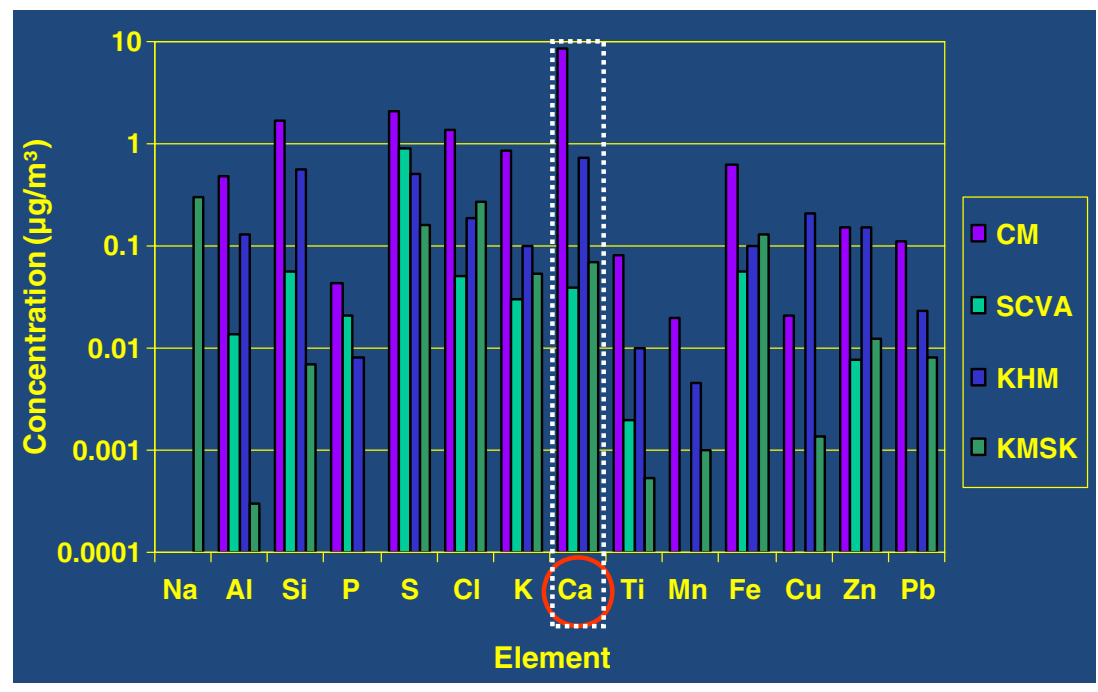

Figure 1. Bulk aerosol concentrations, measured by XRF, in the Correr Museum (CM), Venice, Italy, compared to the Sainsbury Centre for Visual Arts (SCVA) in Norwich, UK, the Cultural History Museum (KHM) in Vienna, Austria, and the Royal Museum of Fine Arts (KMSK) in Antwerp, Belgium. Note the logarithmic scale. 
Minor amounts of $\mathrm{Al}, \mathrm{Si}, \mathrm{Fe}, \mathrm{Cu}, \mathrm{Zn}, \mathrm{Ti}$ and $\mathrm{Mn}$ were also detected. These results are consistent with the single-particle analyses of the aerosol samples and indicate the abundance of the following particle types: Ca-rich particles, sea salt, $\mathrm{CaSO}_{4}$, S-rich particles, aluminosilicates, Si-rich and Fe-rich particles, with the Ca-rich particles being more abundant than the sea salt particles, in Venice. Let us concentrate on the airborne Ca concentrations given in figure 1, which is on a logarithmic scale. Data are given for other museums also: SCVA is the Sainsbury Center for Visual Arts in Norwich, England, KHM is the Cultural History Museum in Vienna, Austria, and KMSK stands for the Royal Museum of Fine Arts in Antwerp, Belgium. It is obvious that the concentrations in the Correr Museum were up to 200 times higher than in the other museums. The bulk atmospheric $\mathrm{Ca}$ concentrations and the relative abundance of the Ca-rich individual particles were higher in winter, and on Mondays when the museum was closed. All these indicate an indoor source in the Bellini room. It is to be noted that the plaster on the walls in these rooms is particularly old or of bad quality. These plaster particles will partially imbed in the paint surface layer, they may adsorb soot and turn dark. Preventive conservation based on the XRS results of the Bellini painting would thus simply imply replacing the plaster rendering in these two rooms.

The dry deposition clearly turned out to be a function of height and position. A sharp decrease in concentration was found with increasing height. Deposition at ground level was around 10 times more than at $5 \mathrm{~m}$. Moreover, the filters attached close to the floor contained relatively more $\mathrm{Si}$ and $\mathrm{Al}$, while the filters attached at a height of several metres contained more $\mathrm{S}$. This can be explained by the deposition of resuspended soil dust close to the floor, and of smaller $\mathrm{CaSO}_{4}$ and S-rich particles at more elevated positions. The deposition measured on filters attached above the door porches was somewhat higher than on filters attached at the end of a room. This can be explained by a higher turbulence and air speed around door porches, resulting in a higher deposition. The same effect can be seen near the paintings. For most of the elements $(\mathrm{Ca}, \mathrm{Fe}, \mathrm{Al}, \mathrm{Cl}$ and $\mathrm{Si})$, indoor/outdoor deposition ratios of about $10 \%$ were found.

\section{The case of the Wawel Castle Museum in Cracow, Poland}

The Wawel Castle is Poland's greatest architectural treasure and a priceless national heritage monument. The rooms of the Renaissance Wawel residence have a truly royal decoration. The valuable collection of Flemish tapestries, amongst other precious artworks, deserve special interest. In 1978, UNESCO placed Wawel Castle on its List of the World's Cultural and Natural Heritage. As the Wawel Castle museum is located in the centre of Cracow, it is in particular, exposed to the harmful effects of external pollution factors. The domestic heating in Cracow is based on coal combustion, regulated individually by the habitants. Moreover, the Wawel Castle is, visited by nearly a million visitors per year.

Samples of the particulate and gaseous matter were collected inside and outside of the Royal Museum in the Wawel Castle in Cracow, in winter and summer, and in different rooms at different floors. Some of the results are published by Worobiec et al [6-8]. In case of particulate matter in general, considering the sufficient and regular cleaning in the exhibition areas, it can be assumed that there are two potential sources of the particles present indoors: visitors and the transport of the outdoor pollutants by the air exchange. 


\section{René van Grieken and Anna Worobiec}

By interpreting the results, it was assumed that there are no other independent indoor pollution sources.

Figure 2 illustrates the effects of visitors in the museum, in winter and summer, on the observed indoor aerosol concentrations, as measured by XRF. Plotted are the concentration ratios on days with visitors versus those on Mondays, when the museum is closed. A ratio of 1 would be indicative of no influence. The ratio is indeed near 1 for some elements (low- $Z$ elements, $\mathrm{Cl}, \mathrm{S}$ ) in summer, but in winter the concentrations are $\sim 20$ times higher than when the museum is open to visitors, particularly for typical pollution elements. In winter, the ambient concentrations are higher in Cracow due to enhanced coal combustion and also due to the frequent temperature inversions. Visitors bring in more air pollution-derived elements that have been deposited on the snow, through their shoes and boots. One preventive conservation measure is to provide more shoe cleaning facilities and mats at the entrance of the museum.

The case of $\mathrm{Cl}$ is remarkable. In summer, there is no influence of visitors, but in winter, the $\mathrm{Cl}$ concentrations are 10 times higher when there are visitors. Cracow is about $600 \mathrm{~km}$ away from the sea. In what form the $\mathrm{Cl}$ is then? Figure 3 shows the ratios, for days with and without visitors, of the relative abundance of different particles discerned by automated EPXMA, for summer and winter and for different floors. It appears that $\mathrm{Cl}$ is present as $\mathrm{NaCl}$ and $\mathrm{NaCl}$ conglomerates with $\mathrm{Ca}$ - and $\mathrm{Fe}$-rich compounds. The relative abundance of these groups is again higher in winter and with tourists. This is caused most probably by street de-icing, hence it can be considered that the Cl-rich particles belong to the coarse particle fraction and are transported inside mainly by tourists.

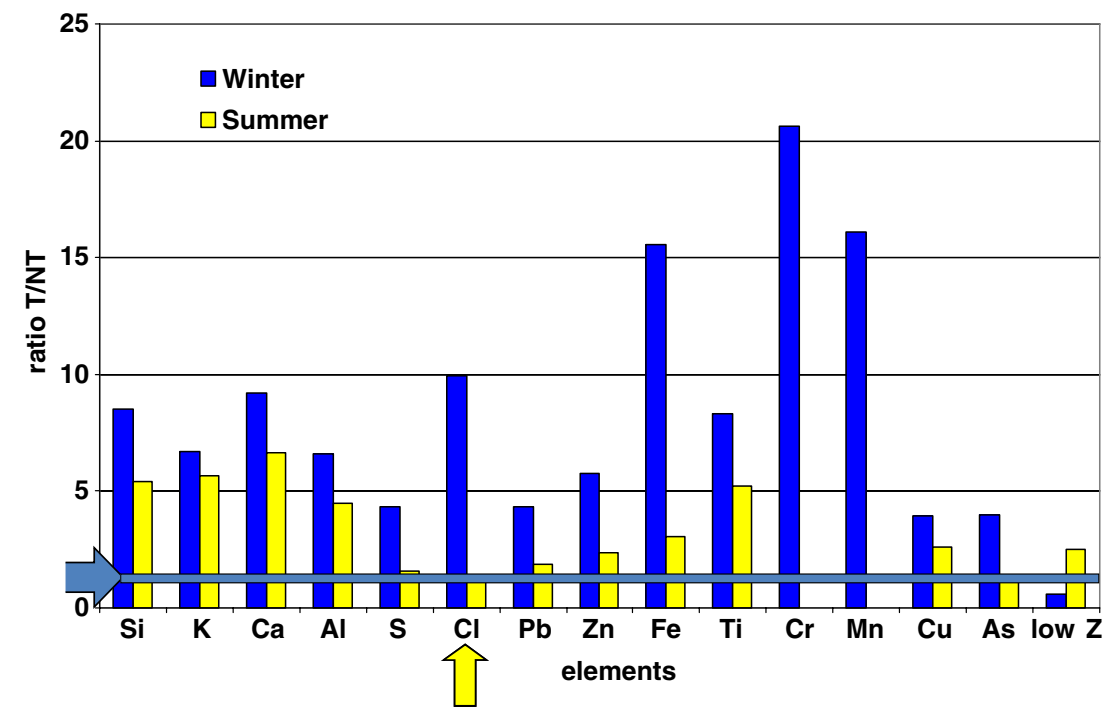

Figure 2. Elemental concentrations ratios for days with and without tourists (T/NT) in the Wawel Castle Museum, Cracow, Poland, for winter and summer, as measured by XRF. If there is no effect of the visitors, the T/NT ratio is 1 . 


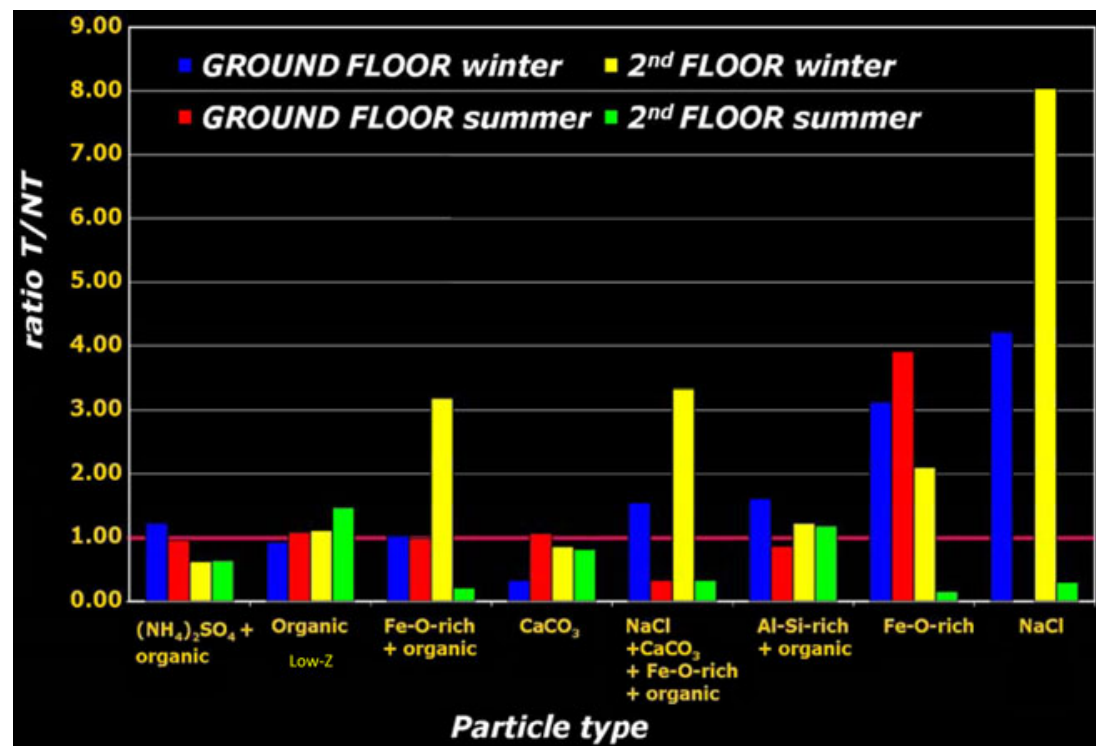

Figure 3. Ratios of the relative abundances for days with and without tourists of the different particle types as determined by EPXMA, for winter and summer and different floors, in the Wawel Castle Museum, Cracow, Poland. If there is no influence of the visitors, the $\mathrm{T} / \mathrm{NT}$ ratio is 1 .

A preventive conservation measurement based on XRS is to stop de-icing with salt in the neighbourhood of the museum. Instead, manual de-icing is now done with shovels.

It can also be seen in figure 3 that the ratio of the low- $Z$ element abundance is independent of the visitors in both seasons and both floors. These particles are mostly organic matter and soot particles, which by their nature belong to the very fine particle fraction and can easily be transported indoors through leaks in windows and doors. This process is independent of the visitors. Micro-Raman confirmed that the smallest particles are indeed soot, in addition to $\left(\mathrm{NH}_{4}\right)_{2} \mathrm{SO}_{4}$, which is a natural global background aerosol. A preventive conservation measure which is now implemented in the Wawel Castle is to seal windows and doors with silicone to prevent soot particles from entering. Since these particles are mostly emitted by diesel cars, an additional measure would be taken to make the neighbourhood of the museum free of vehicular exhausts.

\section{Conclusions}

The results and the conclusions presented in these studies can be extrapolated to other museums sited in ancient buildings with limited possibilities for their insulation from outside, located in cities with extended traffic or in centres where traffic is allowed, and in similar climate conditions (with cold winters) where fossil fuels are used for domestic and industrial purposes. 


\section{René van Grieken and Anna Worobiec}

It is clear that XRS, because of its non-destructive character, plays an important role in studies on $\mathrm{CH}$ items, including their conservation. Also in preventive conservation, XRS has a prominent role since it is ideally suited to measure directly the atmospheric particles on loaded filters and impactor deposits, without any dissolution step. Only two museums are presented here as examples. Similar studies are now carried out, e.g. in the Metropolitan Museum of Arts in New York, USA and in the Alhambra in Granada, Spain.

Future studies are urgently needed concerning the deposition rates of atmospheric pollutants to $\mathrm{CH}$ items, and particularly the interaction process of particles with the surface of $\mathrm{CH}$ items. Indeed, considerable work has already been done on the interaction of pollution gases with $\mathrm{CH}$ items, but with the exception of sea salt, hardly any research has been carried out and published on the direct effects of atmospheric particles.

\section{References}

[1] Z Spolnik, K Belikov, K Van Meel, E Adriaenssens, F De Roeck and R Van Grieken, Appl. Spectrosc. 59, 1465 (2005)

[2] C-U Ro, J Osan, I Szaloki, J de Hoog, A Worobiec and R Van Grieken, Anal. Chem. 75, 851 (2003)

[3] I Bondarenko, B Treiger, R Van Grieken and P Van Espen, Spectrochim. Acta B51, 441 (1996)

[4] L A De Bock, R E Van Grieken, D Camuffo and G W Grime, Environ. Sci. Technol. 30, 3341 (1996)

[5] D Camuffo, P Brimblecombe, R Van Grieken, H-J Busse, G Sturaro, A Valentino, A Bernardi, N Blades, D Shooter, L De Bock, K Gysels, M Wieser and O Kim, Sci. Total Environ. 236, 135 (1999)

[6] A Worobiec, E A Stefaniak, V Kontozova, L Samek, P Karaszkiewicz, K Van Meel and R Van Grieken, e-Preservation Science 3, 63 (2006)

[7] A Worobiec, L Samek, P Karaszkiewicz, V Kontozova-Deutsch, E A Stefaniak, K Van Meel, A Krata, L Bencs and R Van Grieken, Microchem. J. 90, 99 (2008)

[8] A Worobiec, L Samek, A Krata, K Van Meel, B Krupinska, E A Stefaniak, P Karaszkiewicz and R Van Grieken, J. Cultural Heritage 11, 354 (2010) 